\title{
Parent Discipline Practices in an International Sample: Associations With Child Behaviors and Moderation by Perceived Normativeness
}

\author{
Elizabeth T. Gershoff \\ University of Texas at Austin \\ Jennifer E. Lansford \\ Duke University \\ Arnaldo Zelli \\ Istituto Universitario di Scienze Motorie
}

\author{
Andrew Grogan-Kaylor \\ University of Michigan \\ Lei Chang \\ Chinese University of Hong Kong \\ Kirby Deater-Deckard \\ Virginia Polytechnic Institute \\ and State University
}

\author{
Kenneth A. Dodge \\ Duke University
}

\begin{abstract}
This study examined the associations of 11 discipline techniques with children's aggressive and anxious behaviors in an international sample of mothers and children from 6 countries and determined whether any significant associations were moderated by mothers' and children's perceived normativeness of the techniques. Participants included 292 mothers and their 8- to 12-year-old children living in China, India, Italy, Kenya, Philippines, and Thailand. Parallel multilevel and fixed effects models revealed that mothers' use of corporal punishment, expressing disappointment, and yelling were significantly related to more child aggression symptoms, whereas giving a time-out, using corporal punishment, expressing disappointment, and shaming were significantly related to greater child anxiety symptoms. Some moderation of these associations was found for children's perceptions of normativeness.
\end{abstract}

The study of parents' disciplinary practices has been central to developmental psychology for at least the last half century, tracing back to Sears, Maccoby, and Levin's (1957) landmark book, Patterns of Child Rearing. Their study of several hundred White working- and middle-class parents in and around Boston in the 1950s provided the first detailed data on what discipline techniques parents use, why they use them, and how discipline is

Data collection for this work was funded by the Josiah Charles Trent Memorial Foundation and the Duke University Center for Child and Family Policy. We are grateful to the children and parents who participated in this research and to Dario Bacchini, Anna Silvia Bombi, Nandita Chaudhary, Paul Oburu, Kerstin Palmérus, Concetta Pastorelli, Lina Ramos, and Sombat Tapanya for their contributions to data collection. J.E.L. acknowledges support of NICHD Grant R01HD054805. K.A.D. acknowledges support of NIDA Grants K05DA015226 and P30DA023026.

Correspondence concerning this article should be addressed to Elizabeth T. Gershoff, University of Texas at Austin, Department of Human Development and Family Sciences, 1 University Station A2700, Austin, TX 78712. Electronic mail may be sent to liz.gershoff@austin.utexas.edu. linked with children's behaviors. Theirs was one of the first studies to document that, contrary to predictions that controlling parents would have better behaved children, in fact the opposite was true. In the ensuing 50 years, researchers have taken these same themes and tested relations among them in increasingly sophisticated models. What the field has not done consistently is to expand the populations of interest beyond families in the United States, or, in many cases, beyond White, middleclass parents.

The overreliance on children and parents from North America in research on parenting has led to the criticism that the theories and recommendations developed from North American samples are not universal (as they are often assumed to be) and may not apply to parents and children in other

(C) 2010, Copyright the Author(s)

Journal Compilation @ 2010, Society for Research in Child Development, Inc. All rights reserved. 0009-3920/2010/8102-0007 
countries and cultures (Dasen \& Mishra, 2000; Rogoff, 2003). Cultures differ in the value they place on different child qualities and behaviors and in their beliefs about which parenting practices will promote these qualities and behaviors (Bornstein, 1995; Mistry, Chaudhuri, \& Diez, 2003; Ripoll-Nuñez \& Rohner, 2006; Super \& Harkness, 1986). Cultures also differ in their evaluations of what parenting practices are considered to be either physically or emotionally abusive (Korbin, 2003).

Links between cultural values and parents' preferred childrearing practices have indeed been documented. A study of mothers in China and India found that differences in the two groups' use of authoritative and authoritarian parenting practices were related to relative differences in their valuing of goals of social emotional development and honor of the family (Rao, McHale, \& Pearson, 2003). An analysis of ethnographies from 186 preindustrial societies found corporal punishment to be most likely among societies high in social stratification, political integration, long-term use of an alien currency, undemocratic political decision making, and a culture of violence (Ember \& Ember, 2005). Parents in countries with more collectivist orientations, such as China, tend to emphasize the importance of behavioral inhibition and subjugation of individual wants for the good of the family, whereas parents in Western individualist cultures typically value assertiveness and independence in their children (Rothbaum, Morelli, Pott, \& LiuConstant, 2000).

Much of the research on discipline to date, both domestically and internationally, has focused on parents' use of corporal punishment, most likely because corporal punishment is a controversial form of discipline (Gershoff, 2002). However, corporal punishment is but one of many disciplinary techniques parents use in trying to control their children's negative behavior and promote their positive behavior. Although there is great variation in usage, with some parents using it everyday and some never using it, American parents tend to report using corporal punishment relatively rarely, peaking at one and a half times per month when children are 2 years old and decreasing to less than once per month by the time children are 12 years old (Straus \& Stewart, 1999). In a recent longitudinal study of parents' use of 10 different disciplinary tactics, corporal punishment was one of the three least common techniques used by parents of preschoolers (Socolar, Savage, \& Evans, 2007). Most common were monitoring child behavior, talking with children, distracting, and modeling.
In order to understand parental discipline we must expand our focus to the full range of parents' disciplinary techniques, particularly those they use more frequently than corporal punishment. There is very little research on the broad array of parental discipline techniques that are used in non-U.S. countries. The theories behind whether various discipline techniques should or should not be effective in promoting appropriate child behavior have largely been developed by researchers in North America (e.g., Bornstein, 1995; Dodge \& Pettit, 2003; Grusec \& Goodnow, 1994; Hoffman, 1983; Lepper, 1983). Whether parents in other countries differ in their preferences for disciplinary techniques and whether these techniques have similar associations with child behavior across countries remain open questions.

One reason discipline techniques may not have similar effects on children across countries is that the effects may depend on the extent to which the techniques are normative within a culture (DeaterDeckard \& Dodge, 1997). When children perceive a discipline technique to be normative within their culture or community, they may be less likely to evaluate their parents' use of it as aberrant or objectionable. Discipline is most likely to be effective when children perceive it to be fair and reasonable (Grusec \& Goodnow, 1994); if children believe the discipline they received to be out of the range of what their peers receive, they will reject and thus fail to internalize the parents' intended disciplinary message. Discipline that is perceived by children to be nonnormative is likely to be ineffective in promoting appropriate child behavior and may inadvertently lead to increases in problematic child behavior.

Parents' perceptions regarding the normativeness of the techniques they use may also moderate the effects of the techniques on children. When parents perceive a technique to be normative, they may feel more confident and justified in using it and thus may be more likely to use it in a planful and controlled, rather than impulsive and unregulated, manner. The planful, instrumental use of a disciplinary technique is thought to be less likely to cause fear or anxiety in children or to evoke reactive aggression from children (Holden, Miller, \& Harris, 1999; Straus \& Mouradian, 1998).

\section{The Present Study}

In order to advance our understanding of discipline in countries beyond the United States, we collaborated with colleagues in six understudied 
countries, namely, China, India, Italy, Kenya, the Philippines, and Thailand. This sample of countries was diverse on several demographic dimensions, including predominant race/ethnicity and predominant religion. They also varied on several key social and economic indicators, including: gross national income (from highest to lowest: Italy, Thailand, China, Philippines, India, and Kenya, with Italy's income 49 times as large as that of Kenya; World Bank, 2008), individualist versus collectivist social orientation (from most to least individualistic: Italy, India, Philippines, Kenya, China, and Thailand; Hofstede, 2001), and overall child well-being, indexed as the mortality rate for children $<5$ years old, the underweight rate for children $<5$ years old, and the percent of primary-school-aged children not enrolled in school (ranked from best to worst: Italy, China, Thailand, Philippines, Kenya, and India; Save the Children, 2008). Although Italy is first in all three of these rankings, the order of the remaining five countries is not the same for all three indicators, indicating that these countries vary from one another on multiple dimensions. By studying families from each of these countries, we created a diverse international sample with which to examine parent discipline and child behavior.

In a previous study with these data (Lansford et al., 2005), we examined the extent to which the normativeness of harsh corporal punishment (which included spanking, slapping, grabbing, shaking, and beating up) in each of the country subsamples moderated the association between frequency of harsh corporal punishment and children's aggression and anxiety symptoms. More frequent use of harsh corporal punishment was associated with more child aggression and anxiety across all six countries, but the strength of these associations was strongest in country subsamples in which harsh corporal punishment was least normative (Lansford et al., 2005).

Whether children's and mothers' perceptions of cultural normativeness play similar moderational roles for other disciplinary techniques remains unknown. Thus, for this study, we used the same international sample to address two new research questions, namely: (a) When multiple discipline techniques are considered simultaneously, which forms of discipline emerge as having the strongest associations with children's aggressive and anxious behaviors? and (b) Are any significant associations between discipline practices and child behaviors moderated by the extent to which mothers and children perceive these practices to be normative within their communities? We hypothesized that high normativeness will only moderate techniques that are most likely to be experienced as negative events by the child, namely, corporal punishment and yelling. We expected that more benign techniques, such as reasoning, will not be affected by normativeness, although we left open the possibility that less aversive forms of discipline may actually have a stronger impact on children if they are less normative and thus experienced by children as salient positive events.

\section{Method}

\section{Participants}

The sample of 292 families for this study was drawn from a complete project sample of 336 children and their mothers from seven metropolitan areas in six countries: China (Beijing), India (Delhi), Italy (Rome and Naples), Kenya (Rachuonyo District of Nyanza province), Philippines (Manila), and Thailand (Chiang Mai). Within each country, samples were recruited through public schools in neighborhoods that were identified by local contacts as primarily middle class. After permission was obtained from appropriate local authorities (e.g., principals, teachers), children and their parents were invited to participate in a study of how parents discipline children and how parents' behavior affects how children learn and grow. For a family to be eligible for inclusion in the study, both the mother and the child had to be willing to complete the interview.

Although the target age group for the study was mothers and children aged 8-12 years old, the range of ages of children who actually participated was 6-17 $(M=10.57, S D=1.86)$. Because discipline techniques are used differently with children in early childhood, middle childhood, and adolescence and may have different effects depending on the developmental stage in which they are used (Collins, Madsen, \& Susman-Stillman, 2002; GilesSims, Straus, \& Sugarman, 1995), we restricted our sample for these analyses to the target age group of middle childhood (range $=8-12 ; M=10.22, S D=$ 1.30). This restriction resulted in our sample of 292 children and their mothers $(87 \%$ of the original sample) for the analyses reported here. The number of participants and percent of the children who were female in each country-level sample were: China: $n=49,47 \%$ girls; India: $n=36,58 \%$ girls; Italy: $n=73,43 \%$ girls; Kenya: $n=17,53 \%$ girls; Philippines: $n=50$, 38\% girls; and Thailand: $n=58$, $57 \%$ girls. 
Mothers ranged in age from 20 to 59 years $(M=38.66, S D=5.87)$. Although there are ethnic minorities in these countries, the participants did not identify themselves as being members of any ethnic minority groups. In $95 \%$ of the cases, the biological mother was interviewed; in the remaining cases, a female adoptive parent or relative who was the child's primary caregiver was interviewed. Henceforth, we will refer to the parent respondents as "mothers." Within each country, the samples were considered primarily middle class and had similar standings in terms of within-country socioeconomic status. Mothers reported their families' annual income in local currency using ranges that reflected income distributions within a particular country. The median annual income range (converted to U.S. dollars) in each country subsample was as follows: (a) Chinese subsample median $=\$ 2,172-$ $\$ 5,796$ (which may be an underestimate because it does not include bonuses that many Chinese employees earnin addition to their base salary), (b) Indian subsample median $=\$ 13,728-\$ 16,464$, (c) Italian subsample median $=\$ 32,585-\$ 37,799$, (d) Kenyan subsample median $=\$ 1,560-\$ 2,352$, (e) Philippines subsample median $=\$ 3,306-\$ 4,404$, and (f) Thai subsample median $=\$ 3,036-\$ 15,180$. The differences in the width of these income ranges are reflective of the, sometimes widely varying, range of incomes in the communities from which our sub-samples were drawn. Differences in relative income between countries were accounted for by our use of fixed effects models.

\section{Procedure}

All interviews were conducted in the homes of the participants by trained interviewers who were natives of the country. Most of the interviewers were graduate students in psychology and all conducted pilot trials before the actual interview. Before the formal interview began, both the mother and the child gave consent to participate in the interview. During each interview, which lasted about $1 \mathrm{hr}$, the interviewer read aloud each question individually from the printed questionnaire. Because not all participants were literate, all questions were asked orally. After each question was read, the participant verbalized or pointed to the answer on the printed questionnaire or on a separate pictorial response card and responses were recorded by the interviewer. When any participant expressed confusion about a given question, the interviewer provided only brief explanations or elaborations on it, typically consisting of paraphras- ing the question only. The mother and the child were interviewed separately in different rooms or at different times so that they could not hear each other's responses. To minimize social desirability, during the course of the interviews participants were reminded that their answers would be kept confidential, that there were no right or wrong answers to the questions, and that it was important for them to answer as honestly as possible. Country-level differences in social desirability were accounted for, along with all other unmeasured differences between countries, by our use of fixed effects models in the analyses described below.

\section{Measures}

A procedure of translation and back-translation was used to ensure the linguistic and conceptual equivalence of measures across languages. The translators were fluent in English and the target language. Translators were asked to note places in the research instruments that did not translate well, were inappropriate for the age groups in the study, or were culturally insensitive. Any problems noted were resolved through discussions among the translators and investigators. Additionally, the appropriateness of the terms used to assess each form of discipline (e.g., spank, slap, or hit) was evaluated through qualitative interviews with a separate pilot sample of mothers in each country. English versions of the measures were administered in India and the Philippines, countries where English is an official language. Measures in the other countries were administered in Mandarin Chinese, Italian, Dholuo (Kenya), and Thai.

Maternal discipline techniques. The frequency with which mothers reported using each of 11 different types of discipline was assessed through a measure that was developed for the present study, adapted from other instruments that assess parents' discipline strategies (Deater-Deckard, Dodge, \& Sorbring, 2005; Straus, 1979). The discipline questionnaires were introduced by saying, "All children misbehave sometimes. One of the things we need to learn about is what parents do to deal with their children's misbehavior. Think about when your child has misbehaved in the last year." Mothers were then asked a series of questions specific to each discipline technique, such as "How frequently do you teach your child about good and bad behavior? Like, it's not nice to hit, or it's polite to say 'thank you'." Mothers reported how frequently they used each discipline technique on a 5-point 
scale $(1=$ never, 2 = less than once a month, $3=$ about once a month, 4 = about once a week, 5 = almost every day). The 11 discipline techniques as they were described in the interviews, listed in the order they were presented to the mothers and followed by the abbreviations we will use hereafter, were: (1) "teach your child about good and bad behavior" (teach about good and bad behavior); (2) "get your child to apologize or make amends" (get child to apologize); (3) give child a time-out or send him/her to his/her room" (give a time-out); (4) "take away privileges" (take away privileges); (5) "spank, slap, or hit your child" (use corporal punishment); (6) "say you are disappointed with your child, or say that his/her misbehavior hurt your feelings" (express disappointment); (7) "tell your child s/he should be ashamed of her/himself" (shame); (8) "raise your voice, yell, or scold your child" (yell or scold); (9) "tell your child you won't love him/her if he/she acts that way again" (withdraw love for misbehavior); (10) "threaten your child with some punishment" (threaten punishment); and (11) "promise a treat or privilege to your child for good behavior" (promise a treat or privilege). Pooled sample means and country means are reported in Table 1.

Perceived normativeness of discipline techniques. Both mothers and their children were asked a question about how normative they perceived each discipline technique to be in their community. For each of the 11 techniques listed above, mothers were asked a question beginning with the stem, "How frequently do other parents in your community ..." Similarly, children were asked a question beginning with the stem, "When kids do something wrong how often do their parents ..." for each discipline technique. Both parents and children reported how often they thought other parents in their community used each technique according to the same scale mothers used to report the frequency with which they used each discipline technique, namely: $1=$ never, $2=$ less than once a month, 3 = about once a month, $4=$ about once a week, $5=$ almost every day. Mothers' and children's ratings of normativeness were significantly correlated across 10 of the 11 discipline techniques, with the significant correlations ranging from $r(273)=.13, p<.05$, for teach about good and bad behavior, to $r(274)=.46, p<.001$, for give a timeout. Mothers' and children's ratings of the extent to which other parents get children to apologize were the only ratings not significantly correlated, $r(275)=.02, p=.71$. Pooled sample means and country means for mother and child ratings of the normativeness of each discipline technique are reported in Table 1.

Child behaviors. Children's aggression and anxiety behaviors were obtained from mothers' reports using the aggression subscale (20 items) and the Anxiety/Depression subscale (14 items) of the Child Behavior Checklist (CBCL; Achenbach, 1991a). Selfreported symptoms were obtained through youth responses to the Aggression subscale (19 items) and the Anxiety/Depression subscale (16 items) of the Youth Self-Report (YSR; Achenbach, 1991b). The CBCL and YSR have been translated into at least 69 languages, and over 5,000 published studies have used these measures with at least 60 cultural groups (Achenbach, 2004; Crijnen, Achenbach, \& Verhulst, 1997). The Achenbach measures have been used previously in all of the countries involved in the present study: China (e.g., Dong, Wang, \& Ollendick, 2002; Guo et al., 2000), India (Gill \& Kang, 1995; Shenoy, Kapur, \& Kaliaperumal, 1998), Italy (Artigas, 1999), Kenya (Weisz, Sigman, Weiss, \& Mosk, 1993), the Philippines (Florencio, 1988), and Thailand (Weisz, Suwanlert, et al., 1993). In the current study, both subscales had strong internal reliability for the entire sample, for mother and child reports, respectively: aggression $\alpha \mathrm{s}=.80, .80$; anxiety $\alpha \mathrm{s}=.74, .75$. Withincountry internal consistencies for mother and child reports of aggression were: China, $\alpha \mathrm{s}=.79, .80$; India, $\alpha \mathrm{s}=.58, .54 ;$ Italy, $\alpha \mathrm{s}=.67$; Kenya, $\alpha \mathrm{s}=.73$, .81 ; the Philippines, as $=.84, .79$; Thailand, as $=.80$, .83. For the anxiety subscales, internal consistencies for the mother- and child-reports were: China, $\alpha \mathrm{s}=.88, .76$; India, $\alpha \mathrm{s}=.50, .71$; Italy, $\alpha \mathrm{s}=$ .71 ; Kenya, as $=.64, .81$; the Philippines, as $=.81$, .82; Thailand, as $=.69, .71$. Because the YSR was only added to the study after the Italian families had participated, we do not have youth self-ratings of aggression and anxiety for the Italian subsample.

\section{Analyses}

We utilized two complementary analytic approaches in order to account for between-country differences. For each dependent variable, we first estimated a multilevel model, which is suitable for estimating the association of a set of independent variables with a dependent variable of interest. Multilevel models are commonly employed in situations where data are clustered, as in this case where data are clustered by country (Hox, 2002; Raudenbush \& Bryk, 2002). In the multilevel models used in this analysis, the clustering of data is accounted for by allowing the intercept term of the 
Table 1

Within-Country Means of Reported Use of and Perceived Normativeness of 11 Discipline Techniques

\begin{tabular}{|c|c|c|c|c|c|c|c|c|}
\hline & & \multirow{2}{*}{$\begin{array}{l}\text { Pooled } \\
\text { sample } \\
\text { mean }\end{array}$} & \multicolumn{6}{|c|}{ Country } \\
\hline & & & China & India & Italy & Kenya & Philippines & Thailand \\
\hline \multirow{3}{*}{$\begin{array}{l}\text { Teach about } \\
\text { good and } \\
\text { bad behavior }\end{array}$} & Frequency of use & $4.42(0.88)$ & $4.29(0.96)$ & $4.60(0.54)$ & $4.36(0.89)$ & $3.53(1.18)$ & $4.76(0.62)$ & $4.43(0.90)$ \\
\hline & Normativeness (M) & $3.77(1.26)$ & $3.84(1.36)$ & $4.11(0.96)$ & $3.77(1.26)$ & $3.00(1.06)$ & $4.36(0.88)$ & $3.10(1.51)$ \\
\hline & Normativeness (C) & $4.20(1.18)$ & $3.79(1.25)$ & $4.39(0.81)$ & $3.79(1.43)$ & $3.94(1.25)$ & $4.67(0.92)$ & $4.57(0.90)$ \\
\hline \multirow{3}{*}{$\begin{array}{l}\text { Get child to } \\
\text { apologize }\end{array}$} & Frequency of use & $3.50(1.32)$ & $3.10(1.34)$ & $3.04(1.09)$ & $3.31(1.48)$ & $2.65(1.46)$ & $4.18(0.87)$ & 4.07 (1.06) \\
\hline & Normativeness (M) & $3.10(1.31)$ & $2.96(1.45)$ & $2.91(1.00)$ & $3.06(1.33)$ & $2.65(1.11)$ & $3.76(1.04)$ & $2.94(1.53)$ \\
\hline & Normativeness (C) & $3.43(1.38)$ & $2.69(1.21)$ & $3.27(1.19)$ & $3.35(1.56)$ & $3.00(1.41)$ & $4.39(0.73)$ & $3.60(1.36)$ \\
\hline \multirow[t]{3}{*}{ Give a time-out } & Frequency of use & $1.94(1.29)$ & $1.12(0.44)$ & $1.82(1.12)$ & $1.53(0.95)$ & $1.82(1.07)$ & $3.86(0.95)$ & $1.64(1.00)$ \\
\hline & Normativeness (M) & $2.18(1.27)$ & $1.35(0.80)$ & $2.20(1.01)$ & $2.20(1.11)$ & $2.00(1.50)$ & $3.80(0.78)$ & $1.35(0.66)$ \\
\hline & Normativeness (C) & $2.12(1.35)$ & $1.57(1.02)$ & $1.84(1.21)$ & $2.29(1.36)$ & $1.59(1.00)$ & $3.80(0.89)$ & $1.31(0.73)$ \\
\hline \multirow{3}{*}{$\begin{array}{l}\text { Take away } \\
\text { privileges }\end{array}$} & Frequency of use & $2.35(1.21)$ & $2.02(1.09)$ & $2.13(1.16)$ & $2.33(1.24)$ & $1.47(0.87)$ & $3.20(0.95)$ & $2.33(1.22)$ \\
\hline & Normativeness (M) & $2.47(1.22)$ & $2.02(1.14)$ & $2.38(1.25)$ & $2.93(1.08)$ & $1.65(1.00)$ & $3.24(0.87)$ & 1.77 (1.15) \\
\hline & Normativeness (C) & $2.36(1.36)$ & $1.94(1.28)$ & $2.00(1.38)$ & $2.71(1.35)$ & $1.65(1.46)$ & $3.28(1.28)$ & $2.02(1.18)$ \\
\hline \multirow{3}{*}{$\begin{array}{l}\text { Use corporal } \\
\text { punishment }\end{array}$} & Frequency of use & $2.03(1.02)$ & $1.86(1.00)$ & $2.31(1.08)$ & $2.15(0.94)$ & $3.06(0.97)$ & $2.04(1.09)$ & $1.52(0.71)$ \\
\hline & Normativeness (M) & $2.47(1.16)$ & $1.66(0.83)$ & $2.68(1.03)$ & $2.97(1.12)$ & $3.41(1.06)$ & $2.76(0.98)$ & $1.71(0.97)$ \\
\hline & Normativeness (C) & $2.29(1.33)$ & $1.75(1.16)$ & $2.38(1.11)$ & $3.21(1.36)$ & $3.82(1.13)$ & $1.86(0.98)$ & $1.48(0.75)$ \\
\hline \multirow{3}{*}{$\begin{array}{l}\text { Express } \\
\text { disappointment }\end{array}$} & Frequency of use & $2.51(1.18)$ & $2.10(1.21)$ & $2.87(0.92)$ & $2.56(1.22)$ & $2.59(1.42)$ & $2.44(1.28)$ & $2.57(1.03)$ \\
\hline & Normativeness (M) & $2.59(1.23)$ & $1.89(0.98)$ & $3.05(0.94)$ & $2.88(1.15)$ & $3.00(1.41)$ & $3.02(1.23)$ & $1.84(1.12)$ \\
\hline & Normativeness (C) & $2.39(1.30)$ & $1.96(1.15)$ & $2.69(1.28)$ & $2.63(1.40)$ & $2.76(1.48)$ & $2.24(1.32)$ & $2.24(1.11)$ \\
\hline \multirow[t]{3}{*}{ Shame } & Frequency of use & $2.21(1.17)$ & $1.82(1.20)$ & $2.71(1.06)$ & $2.36(1.26)$ & $2.71(1.05)$ & $1.96(1.01)$ & $2.02(1.08)$ \\
\hline & Normativeness (M) & $2.38(1.21)$ & $1.72(1.03)$ & $2.95(1.01)$ & $2.67(1.27)$ & $2.88(0.86)$ & $2.69(1.23)$ & $1.60(0.90)$ \\
\hline & Normativeness (C) & $2.41(1.33)$ & $1.71(1.05)$ & $2.56(1.12)$ & $3.01(1.46)$ & $3.75(1.13)$ & $2.00(1.10)$ & $2.12(1.17)$ \\
\hline \multirow[t]{3}{*}{ Yell or scold } & Frequency of use & $3.26(1.27)$ & $2.82(1.18)$ & $3.29(0.92)$ & $4.21(1.05)$ & $3.06(1.34)$ & $3.06(1.42)$ & $2.69(1.06)$ \\
\hline & Normativeness (M) & $3.35(1.26)$ & $2.45(1.23)$ & $3.54(0.70)$ & $4.27(0.96)$ & $3.06(1.03)$ & 3.34 (1.17) & $2.78(1.35)$ \\
\hline & Normativeness (C) & $2.86(1.37)$ & $2.02(1.16)$ & $2.96(1.21)$ & $3.59(1.31)$ & $3.88(1.45)$ & $2.94(1.20)$ & $2.28(1.20)$ \\
\hline \multirow{3}{*}{$\begin{array}{l}\text { Withdraw love } \\
\text { for misbehavior }\end{array}$} & Frequency of use & $1.83(1.15)$ & $2.06(1.36)$ & $2.31(1.24)$ & $1.41(0.79)$ & $2.06(1.43)$ & $1.50(0.81)$ & 1.98 (1.19) \\
\hline & Normativeness (M) & $2.00(1.10)$ & $1.89(1.09)$ & $2.54(1.09)$ & $1.87(1.08)$ & $2.24(1.25)$ & $2.02(0.92)$ & 1.67 (1.09) \\
\hline & Normativeness (C) & $1.71(1.08)$ & $1.41(0.93)$ & $1.91(1.04)$ & $1.67(1.05)$ & $2.24(1.25)$ & 1.80 (1.17) & 1.65 (1.08) \\
\hline \multirow{3}{*}{$\begin{array}{l}\text { Threaten } \\
\text { punishment }\end{array}$} & Frequency of use & $2.64(1.28)$ & $1.94(1.20)$ & $2.38(1.07)$ & $2.85(1.35)$ & $4.12(1.22)$ & $2.82(1.12)$ & $2.59(1.12)$ \\
\hline & Normativeness (M) & $2.78(1.36)$ & $1.63(0.95)$ & $2.61(1.04)$ & 3.19 (1.32) & $4.53(1.01)$ & $3.20(1.05)$ & $2.38(1.34)$ \\
\hline & Normativeness (C) & $2.32(1.39)$ & $1.57(1.04)$ & $1.91(1.10)$ & $2.53(1.42)$ & $4.71(0.77)$ & $2.79(1.15)$ & $1.93(1.17)$ \\
\hline \multirow{3}{*}{$\begin{array}{l}\text { Promise a treat } \\
\text { or privilege }\end{array}$} & Frequency of use & $3.07(1.33)$ & $2.46(1.34)$ & $3.56(0.97)$ & $2.65(1.40)$ & $2.12(1.62)$ & $3.80(0.88)$ & $3.34(1.16)$ \\
\hline & Normativeness (M) & $3.05(1.27)$ & $2.42(1.30)$ & $3.72(0.83)$ & $3.40(1.16)$ & $2.31(1.45)$ & $3.36(0.88)$ & $2.48(1.43)$ \\
\hline & Normativeness (C) & $3.28(1.42)$ & $1.92(1.15)$ & $3.49(0.85)$ & $3.60(1.46)$ & $1.71(1.36)$ & $3.94(1.00)$ & $3.78(1.17)$ \\
\hline
\end{tabular}

Note. Scale values are: $1=$ never, 2 = less than once a month, $3=$ about once a month, $4=$ about once a week, $5=$ almost every day. $\mathrm{M}=$ mother report; $\mathrm{C}=$ child report. Means are presented with standard deviations in parentheses.

model to randomly vary across countries (Raudenbush \& Bryk, 2002; Stata Corporation, 2005). Multilevel models estimate both within country and between country differences (Raudenbush \& Bryk, 2002). In other words, there may be differences in parenting and child behavior between two families in the same country, but there may also be differences in parenting and child behavior across countries. Both sources of variation are incorporated into the parameters of the multilevel models.

However, one drawback of using multilevel models for this project is that with a relatively small number of Level 2 units (six countries), the distributional assumptions necessary for estimation of a random intercept may not be satisfied (Maas \& Hox, 2004). Therefore, for each dependent variable we also estimated a fixed effects model. As the name of these models suggests, country-specific intercepts are estimated as fixed, rather than random, and thus the models are not subject to the same distributional concerns as multilevel models. In addition, fixed effect models are able to control for both observed and unobserved country subsample-level differences (Allison, 2005). One potential limitation of fixed effects models is that all between-country differences are subsumed into the 
country-specific terms, and the parameter estimates of the model only reflect differences between individuals in the same countries. In the present article, we conducted parallel multilevel and fixed effects analyses in order to identify and understand potential moderation by country of residence in the most robust manner.

Because the country subsamples were small and were not chosen to be representative of their respective countries, we cannot extrapolate any subsample differences up to country-level differences. Our emphasis in these analyses is on whether country of residence explains any significant portion of the associations of 11 discipline techniques with child mental health and behavior. We cannot make conclusions about any given country included in our study, but rather treat ours as an international sample with which to determine whether the associations of parental discipline with child mental health and behavior are culture- (i.e., country-) specific or potentially universal.

\section{Results}

\section{Discipline Techniques in Relation to Children's Aggression and Anxiety Across Countries}

Table 2 summarizes the results for the models in which mother- and child-reported aggression were regressed on the 11 discipline techniques considered simultaneously; all models control for children's gender and age. The significant intercepts for country variance in both multilevel models (intercepts $=0.48$ and 0.46 , both $p \mathrm{~s}<.01$ ) indicate that there are country-level differences in average levels of child aggression across the countries,

Table 2

Results of Multilevel and Fixed Effects Models Predicting Children's Aggression Symptoms From Mothers' Reported Frequency of Using 11 Discipline Techniques in Six Countries

\begin{tabular}{|c|c|c|c|c|c|c|c|c|}
\hline & \multicolumn{4}{|c|}{ Child aggression-Mother reports } & \multicolumn{4}{|c|}{ Child aggression-Self reports } \\
\hline & \multicolumn{2}{|c|}{$\begin{array}{l}\text { Multilevel } \\
\text { model }\end{array}$} & \multicolumn{2}{|c|}{$\begin{array}{c}\text { Fixed effects } \\
\text { model }\end{array}$} & \multicolumn{2}{|c|}{$\begin{array}{l}\text { Multilevel } \\
\text { model }\end{array}$} & \multicolumn{2}{|c|}{$\begin{array}{c}\text { Fixed effects } \\
\text { model }\end{array}$} \\
\hline & $\beta$ & $S E$ & $\beta$ & $S E$ & $\beta$ & $S E$ & $\beta$ & $S E$ \\
\hline \multicolumn{9}{|l|}{ Fixed effects } \\
\hline Intercept & $-1.72^{* *}$ & 0.52 & $-1.57^{* *}$ & 0.49 & -0.54 & 0.07 & -0.31 & 0.70 \\
\hline Child gender ${ }^{\mathrm{a}}$ & $-0.25^{* *}$ & 0.10 & $-0.24^{* *}$ & 0.10 & -0.03 & 0.13 & -0.02 & 0.13 \\
\hline Child's age & -0.00 & 0.04 & 0.00 & 0.04 & -0.03 & 0.05 & -0.03 & 0.05 \\
\hline Teach about good and bad behavior & 0.02 & 0.06 & 0.01 & 0.06 & -0.12 & 0.09 & -0.13 & 0.09 \\
\hline Get child to apologize & -0.01 & 0.05 & -0.02 & 0.05 & -0.04 & 0.07 & -0.05 & 0.07 \\
\hline Give a time-out & 0.05 & 0.05 & 0.04 & 0.05 & 0.10 & 0.07 & 0.08 & 0.07 \\
\hline Take away privileges & 0.06 & 0.05 & 0.05 & 0.05 & 0.02 & 0.07 & -0.01 & 0.07 \\
\hline Use corporal punishment & $0.17^{* *}$ & 0.05 & $0.18^{* *}$ & 0.05 & 0.15 & 0.08 & $0.16^{*}$ & 0.08 \\
\hline Express disappointment & $0.13^{* *}$ & 0.05 & $0.13^{* *}$ & 0.05 & 0.09 & 0.07 & 0.10 & 0.07 \\
\hline Shame & 0.08 & 0.05 & 0.09 & 0.05 & -0.02 & 0.07 & -0.00 & 0.08 \\
\hline Yell or scold & $0.14^{* *}$ & 0.05 & $0.13^{* *}$ & 0.05 & $0.21^{* *}$ & 0.06 & $0.20^{* *}$ & 0.06 \\
\hline Withdraw love for misbehavior & 0.04 & 0.05 & 0.04 & 0.05 & 0.04 & 0.07 & 0.04 & 0.07 \\
\hline Threaten punishment & 0.05 & 0.05 & 0.06 & 0.05 & 0.01 & 0.07 & 0.04 & 0.07 \\
\hline Promise a treat or privilege & -0.02 & 0.04 & -0.02 & 0.04 & -0.00 & 0.06 & -0.02 & 0.06 \\
\hline \multicolumn{9}{|l|}{ Random effects for multilevel models } \\
\hline Intercept for country variance & $0.48^{* *}$ & 0.17 & - & & $0.46^{* *}$ & 0.22 & - & \\
\hline Residual variance & $0.76^{* *}$ & 0.03 & - & & $0.90^{* *}$ & 0.05 & - & \\
\hline \multicolumn{9}{|l|}{ Fit indices for fixed effects models } \\
\hline$R^{2}$ & - & & 0.47 & & - & & 0.28 & \\
\hline Root mean square error & - & & 0.76 & & - & & 0.90 & \\
\hline$F$ & & & $9.33^{* * *}$ & 256) & & & $3.47^{* * *}$ & 188) \\
\hline
\end{tabular}

Note. Standardized coefficients and their standard errors are presented. The models for mother-rated outcomes included 275 families in the six countries. Because the Youth Self-Report was not asked of children in the Italian sample, the models for child-rated outcomes include 206 families and five countries.

${ }^{\mathrm{a}} 0=$ boys, 1 = girls.

${ }^{*} p<.05 .{ }^{* *} p<.01{ }^{* * *} p<.001$. 
while the significant $R^{2} \mathrm{~s}$ from the fixed effects models $\left(R^{2} \mathrm{~s}=0.47\right.$ and 0.28 , both $\left.p \mathrm{~s}<.001\right)$ indicate that parent discipline techniques do a good job explaining the variance in child aggression, with $47 \%$ of the variance in mother-reported aggression explained and $28 \%$ of child-reported aggression explained. Mothers rated their boys as more aggressive than did mothers of girls; however, there were no gender differences in child-reported symptoms of aggression.

The results from the multilevel and fixed effects models were consistent-in all but one case (childreported aggression as a function of mothers' use corporal punishment in the multilevel model), all coefficients significant in the multilevel model were also significant in the fixed effects model. Across both the multilevel and fixed effects models, the more often mothers use corporal punishment, the more aggressive they reported their children were $(\beta \mathrm{s}=.17$ and .18, $p<.01$, for the multilevel and fixed effects models, respectively). The frequency with which mothers yell or scold was significantly associated with mothers' ratings of children's aggression ( $\beta \mathrm{s}=.14$ and $.13, p<.01$, in the multilevel and fixed effects models). Both use corporal punishment and yell or scold similarly were associated with children's self-reported aggression, although corporal punishment was not significant in the multilevel model $(\beta=.15, n s$, and $\beta=.16, p<.05$, for use corporal punishment in the multilevel and fixed effects models; $\beta s=.21$ and $.20, p<.01$, for yell or scold). The extent to which mothers reported that they express disappointment was associated with more mother-reported aggression $(\beta=.13, p<.01$, in both models), but not with more child-reported aggression $(\beta s=.09$ and $.10, n s)$. The remaining eight discipline techniques were not significantly associated with child aggression in any of the models.

Results from the multilevel and fixed effects models for the dependent variables of mother- and child-reported anxiety symptoms while controlling for child gender and age are presented in Table 3. As with the models for child aggression symptoms, the results from the multilevel and fixed effects models for child anxiety symptoms were generally the same. The one difference was again for use corporal punishment, which was significantly associated with child-reported anxiety symptoms in the fixed effects model $(\beta=.17, p<.05)$ but not in the multilevel model $(\beta=.15, n s)$. The 11 discipline techniques did a fair job accounting for child anxiety symptoms, explaining $34 \%$ of the variance in mother-reported symptoms and 19\% of the variance in child-reported symptoms. Different disci- pline techniques were significant in relation to mother- versus child-reported anxiety symptoms. In the mother-reported models, the frequency with which mothers give a time-out was significantly correlated with child anxiety symptoms $(\beta s=.13$ and $.14, p<.05$, respectively, for the multilevel and fixed effects models) as was the frequency with which mothers shame their children $(\beta=.12$, $p<.05$, in both models). In the models with children's own reports of their anxiety symptoms as the dependent variable, the frequency with which mothers report they use corporal punishment was significant in the fixed effects model only $(\beta=.17$, $p<.05)$ while express disappointment was significantly associated with children's anxious behaviors in both models ( $\beta=.15, p<.05$, in both models). Seven discipline techniques were not associated with child anxiety symptoms in any of the four models tested.

For all forms of discipline in the multilevel models statistically significant at $p<.05$, models were re-estimated with random slope parameters in order to see whether there was variation in the significant slopes by country. In only two cases did a likelihood ratio test indicate that there was statistically significant variation by country in the slope parameter for a specific discipline type. There was statistically significant variation in the slope for the association of use corporal punishment with child-rated aggression and in the slope for the association of express disappointment with mother-rated aggression. Both of these models were then re-estimated with country differences treated as fixed in order to examine countryspecific slopes.

A fixed effects model examining country-specific slopes for the association of use corporal punishment with child-rated aggression did not find any statistically significant country-level variation in the slope. This finding indicates that the variation in slope found in the multilevel model might have been due to the distributional assumptions required by multilevel models or to unobserved differences between countries. In contrast, results from these fixed effects models suggested that express disappointment was more strongly associated with increased levels of mother-rated aggression among families in the Chinese, Italian, Philippine, and Thai subsample than among families in the Kenyan subsample. Express disappointment was more strongly associated with mother-rated aggression for families in the Chinese subsample than for families in the Indian subsample. However, across all country subsamples, more frequent use of 
Table 3

Results of Multilevel and Fixed Effects Models Predicting Children's Anxiety Symptoms From Mothers' Reported Frequency of Using 11 Discipline Techniques in Six Countries

\begin{tabular}{|c|c|c|c|c|c|c|c|c|}
\hline & \multicolumn{4}{|c|}{ Child anxiety-Mother report } & \multicolumn{4}{|c|}{ Child anxiety—Self report } \\
\hline & \multicolumn{2}{|c|}{$\begin{array}{l}\text { Multilevel } \\
\text { model }\end{array}$} & \multicolumn{2}{|c|}{$\begin{array}{c}\text { Fixed effects } \\
\text { model }\end{array}$} & \multicolumn{2}{|c|}{$\begin{array}{l}\text { Multilevel } \\
\text { model }\end{array}$} & \multicolumn{2}{|c|}{$\begin{array}{c}\text { Fixed effects } \\
\text { model }\end{array}$} \\
\hline & $\beta$ & $S E$ & $\beta$ & $S E$ & $\beta$ & $S E$ & $\beta$ & $S E$ \\
\hline \multicolumn{9}{|l|}{ Fixed effects } \\
\hline Intercept & $-2.79^{* *}$ & 0.56 & $-2.72^{* *}$ & 0.55 & -1.37 & 0.76 & -1.25 & 0.74 \\
\hline Child gender ${ }^{a}$ & 0.18 & 0.11 & 0.17 & 0.11 & 0.26 & 0.14 & 0.26 & 0.14 \\
\hline Child's age & $0.10^{*}$ & 0.04 & $0.11^{*}$ & 0.04 & 0.05 & 0.05 & 0.05 & 0.05 \\
\hline Teach about good and bad behavior & 0.03 & 0.07 & 0.03 & 0.07 & -0.05 & 0.10 & -0.07 & 0.10 \\
\hline Get child to apologize & -0.03 & 0.05 & -0.03 & 0.05 & -0.02 & 0.08 & -0.03 & 0.08 \\
\hline Give a time-out & $0.13^{*}$ & 0.06 & $0.14^{*}$ & 0.06 & 0.04 & 0.07 & 0.04 & 0.08 \\
\hline Take away privileges & 0.07 & 0.05 & 0.06 & 0.05 & 0.09 & 0.07 & 0.07 & 0.07 \\
\hline Use corporal punishment & 0.11 & 0.06 & 0.12 & 0.06 & 0.15 & 0.08 & $0.17^{*}$ & 0.08 \\
\hline Express disappointment & 0.08 & 0.06 & 0.08 & 0.06 & $0.15^{*}$ & 0.07 & $0.15^{*}$ & 0.07 \\
\hline Shame & $0.12^{*}$ & 0.06 & $0.12^{*}$ & 0.06 & -0.06 & 0.08 & -0.06 & 0.08 \\
\hline Yell or scold & 0.09 & 0.05 & 0.08 & 0.05 & 0.07 & 0.07 & 0.05 & 0.07 \\
\hline Withdraw love for misbehavior & 0.09 & 0.06 & 0.10 & 0.06 & -0.10 & 0.07 & -0.11 & 0.07 \\
\hline Threaten punishment & -0.04 & 0.06 & -0.03 & 0.06 & 0.08 & 0.07 & 0.11 & 0.08 \\
\hline Promise a treat or privilege & 0.01 & 0.05 & 0.02 & 0.05 & -0.03 & 0.07 & -0.04 & 0.07 \\
\hline \multicolumn{9}{|l|}{ Random effects for multilevel models } \\
\hline Intercept for country variance & $0.41^{* *}$ & 0.15 & - & & $0.38^{* *}$ & 0.18 & & \\
\hline Residual variance & $0.85^{* *}$ & 0.04 & - & & $0.96^{* *}$ & 0.05 & & \\
\hline \multicolumn{9}{|l|}{ Fit indices for fixed effects models } \\
\hline$R^{2}$ & - & & 0.34 & & - & & 0.19 & \\
\hline Root mean square error & - & & 0.85 & & - & & 0.96 & \\
\hline$F$ & & & $5.76^{* * *}$ & 256) & & & $2.05^{*}$ & 188) \\
\hline
\end{tabular}

Note. Standardized coefficients and their standard errors are presented. The models for mother-rated outcomes included 275 families in the six countries. Because the Youth Self-Report was not asked of children in the Italian sample, the models for child-rated outcomes include 206 families and five countries.

${ }^{\mathrm{a}} 0=$ boys, 1 = girls.

${ }^{*} p<.05 .{ }^{* *} p<.01{ }^{* * *} p<.001$.

express disappointment was associated with higher levels of aggression.

Perceived Normativeness as a Moderator of Associations Among Discipline Techniques and Children's Aggression and Anxiety

To examine whether mothers' and children's perceptions of the normativeness of discipline techniques moderated their associations with child behavior, we focused on the discipline techniques that were significant main effects in either the multilevel or the fixed effects models for the child aggression and anxiety dependent variables in Tables 2 and 3. We thus examined the potential for perceived normativeness to moderate the statistically significant relations between 5 of the 11 discipline techniques and one or both of the child behaviors. Specifically, we focused on the associations of give a time-out with mother-rated anxiety, use corporal punishment with mother- and childreported aggression and child-reported anxiety, express disappointment with mother-reported aggression and child-reported anxiety, shame with mother-rated anxiety, and yell or scold with motherand child-reported aggression. For each of these nine discipline-outcome combinations, we ran the models separately for moderation by mother-perceived normativeness and by child-perceived normativeness. Employing a similar approach to that used above, each model was run as a multilevel model and then again as a fixed effects model; in all cases, the results were nearly identical for each approach. For ease of interpretation, we present and discuss only the results from the multilevel models. 
Table 4 displays the results from the tests of moderation by mother-reported normativeness. Each of these models controlled for child age and child gender. In only one of the models was the main effect for mother-reported normativeness significant as well as the interaction term. The more normative mothers thought express disappointment was in their community, the more anxiety symptoms their children self-reported. The significant negative interaction term between the frequency with which mothers express disappointment and how normative they perceived it to be, $\beta=-.12$, $p<.001$, is graphed in Figure 1. The slope of the regression line between frequency with which mothers express disappointment and the number of anxiety symptoms reported by their children is steeper under conditions of low normativeness than under high normativeness. The intercept was higher for the high normativeness condition.

Children's perceived normativeness of various discipline techniques was a stronger moderator of the associations between discipline and child behavior; it was significant in five of the nine models tested (see Table 5). Children's perceptions of the normativeness of corporal punishment

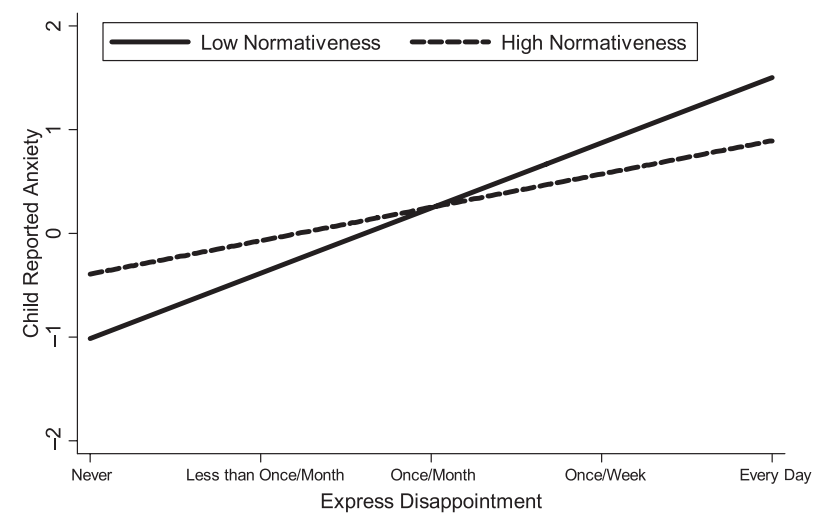

Figure 1. Plot of the link between frequency of mothers' expressions of disappointment and children's anxiety symptoms as moderated by mothers' perceptions of the normativeness of expressing disappointment.

Note. "Low normativeness" and "high normativeness" reflect the frequency with which mothers express disappointment at -1 and $+1 S D$, respectively, from the mean of mothers' reports of normativeness across the sample.

significantly moderated the associations of mothers' use of corporal punishment with children's aggression and anxiety, $\beta \mathrm{s}=-.07,-.14$, and -.10 . Graphs

Table 4

Results of Multilevel Models Predicting Children's Aggression and Anxiety Symptoms From Significant Discipline Techniques Moderated by Mothers' Perceived Normativeness

\begin{tabular}{|c|c|c|c|c|}
\hline & \multicolumn{2}{|c|}{ Child aggression } & \multicolumn{2}{|c|}{ Child anxiety } \\
\hline & Mother report & Child report & Mother report & Child report \\
\hline \multicolumn{5}{|l|}{ Give a time-out } \\
\hline Frequency with which mother gives a time-out & & & $.20(.13)$ & \\
\hline Mother's perceived normativeness of time-out & & & $.00(.10)$ & \\
\hline Interaction & & & $.01(.04)$ & \\
\hline \multicolumn{5}{|l|}{ Use corporal punishment } \\
\hline Frequency with which mother uses corporal punishment & $.28^{* *}(.12)$ & $.29 *(.15)$ & & $.19 \quad(.16)$ \\
\hline Mother's perceived normativeness of corporal punishment & $.14 \quad(.10)$ & $-.06(.13)$ & & $-.02 \quad(.14)$ \\
\hline Interaction & $-.01 \quad(.04)$ & $.01(.05)$ & & $.01 \quad(.05)$ \\
\hline \multicolumn{5}{|l|}{ Express disappointment } \\
\hline Frequency with which mother expresses disappointment & $.17 \quad(.11)$ & & & $.48^{* * *}(.14)$ \\
\hline $\begin{array}{l}\text { Mother's perceived normativeness of expressing } \\
\text { disappointment }\end{array}$ & $-.10 \quad(.10)$ & & & $.38^{* *}(.15)$ \\
\hline Interaction & $.03 \quad(.03)$ & & & $-.12^{* * *}(.05)$ \\
\hline \multicolumn{5}{|l|}{ Shame } \\
\hline Frequency with which mother shames & & & $.06(.11)$ & \\
\hline Mother's perceived normativeness of shaming & & & $-.08(.11)$ & \\
\hline Interaction & & & $.05(.04)$ & \\
\hline \multicolumn{5}{|l|}{ Yell or scold } \\
\hline Frequency with which mother yells or scolds & $.21^{*}(.12)$ & $.17(.15)$ & & \\
\hline Mother's perceived normativeness of yelling or scolding & $-.02 \quad(.12)$ & $-.13(.15)$ & & \\
\hline Interaction & $.01 \quad(.03)$ & $.04(.04)$ & & \\
\hline
\end{tabular}

Note. All models controlled for child age and child gender. Values presented are standardized with standard errors in parentheses. ${ }^{*} p<.05 .{ }^{* *} p<.01 .{ }^{* * *} p<.001$. 
Table 5

Results of Multilevel Models Predicting Child Aggression and Anxiety Symptoms From Significant Discipline Techniques Moderated by Children's Perceived Normativeness

\begin{tabular}{|c|c|c|c|c|}
\hline & \multicolumn{2}{|c|}{ Child aggression } & \multicolumn{2}{|c|}{ Child anxiety } \\
\hline & Mother report & Child report & Mother report & Child report \\
\hline \multicolumn{5}{|l|}{ Give at time-out } \\
\hline Frequency with which mother gives a time-out & & & $.16 \quad(.10)$ & \\
\hline Child's perceived normativeness of time-out & & & $.02 \quad(.09)$ & \\
\hline Interaction & & & $.02 \quad(.03)$ & \\
\hline \multicolumn{5}{|l|}{ Use corporal punishment } \\
\hline Frequency with which mother uses corporal punishment & $.51^{* * *}(.11)$ & $.49^{* * *}(.14)$ & & $.40^{* * *}(.15)$ \\
\hline Child's perceived normativeness of corporal punishment & $.17^{*}(.09)$ & $.57^{* * *}(.13)$ & & $.35^{* *}(.14)$ \\
\hline Interaction & $-.07^{*} \quad(.04)$ & $-.14^{* * *}(.05)$ & & $-.10^{*}(.05)$ \\
\hline \multicolumn{5}{|l|}{ Express disappointment } \\
\hline Frequency with which mother expresses disappointment & $.35^{* * *}(.09)$ & & & $.54^{* * *}(.11)$ \\
\hline Child's perceived normativeness of expressing disappointment & $.13 \quad(.09)$ & & & $.72^{* * *}(.12)$ \\
\hline Interaction & $-.03 \quad(.03)$ & & & $-.19^{* * *}(.04)$ \\
\hline \multicolumn{5}{|l|}{ Shame } \\
\hline Frequency with which mother shames & & & $.24^{* *}(.10)$ & \\
\hline Child's perceived normativeness of shaming & & & $.01 \quad(.10)$ & \\
\hline Interaction & & & $.00 \quad(.03)$ & \\
\hline \multicolumn{5}{|l|}{ Yell or scold } \\
\hline Frequency with which mother yells or scolds & $.44^{* * *}(.09)$ & $.15 \quad(.12)$ & & \\
\hline Child's perceived normativeness of yelling or scolding & $.23^{* *}(.10)$ & $.11 \quad(.13)$ & & \\
\hline Interaction & $-.06^{* *}(.03)$ & $.02 \quad(.04)$ & & \\
\hline
\end{tabular}

Note. All models controlled for child age and child gender. Values presented are standardized with standard errors in parentheses. ${ }^{*} p<.05 .{ }^{* *} p<.01 .{ }^{* * *} p<.001$.

of these significant interactions are presented in Figure 2. The slope of the regression line under the condition of low normativeness was steeper than that for high normativeness in each case. These findings suggest that although more frequent corporal punishment is associated with more child- and mother-rated aggression and child-rated anxiety in both conditions, mothers' use of corporal punishment is less strongly associated with child behaviors when children believe it to be normative in their communities.

Similar results were found for moderation of express disappointment and yell or scold. In both cases, the interaction of child-perceived normativeness with the frequency with which mothers used each technique was negative $(\beta=-.19, p<.001$, and $\beta=-.06, p<.01)$, indicating a decreased slope. The graphs of these interactions are displayed in the right half of Figure 2. As with the other interaction terms, the slopes of the regression lines under highnormativeness conditions are less steep than the slopes of the lines under the low-normativeness condition. Also of interest is that, similar to the other graphs, the intercept is higher under the high-normativeness condition.

\section{Discussion}

This study examined the disciplinary practices of mothers in six countries as well as the associations of these discipline techniques with child aggression and anxiety. In parallel analyses with country of residence treated as a random intercept (in multilevel models) and as a fixed parameter (in fixed effects models), we tested the extent to which the associations of maternal discipline techniques with children's aggressive and anxious symptoms are culture (country) specific or universal across countries. We also examined the extent to which perceived normativeness of a given discipline technique might moderate these links. Our goal in this manuscript was to examine links between a range of discipline techniques and child aggression and anxiety in a unique, international sample, with country differences treated by our choice of analytic techniques. In other words, our intention was not to treat this as an opportunity to make generalizations about parents in particular countries.

Our first research question was, once you take into account that parents differ by country in their preferred discipline techniques, is each form of 

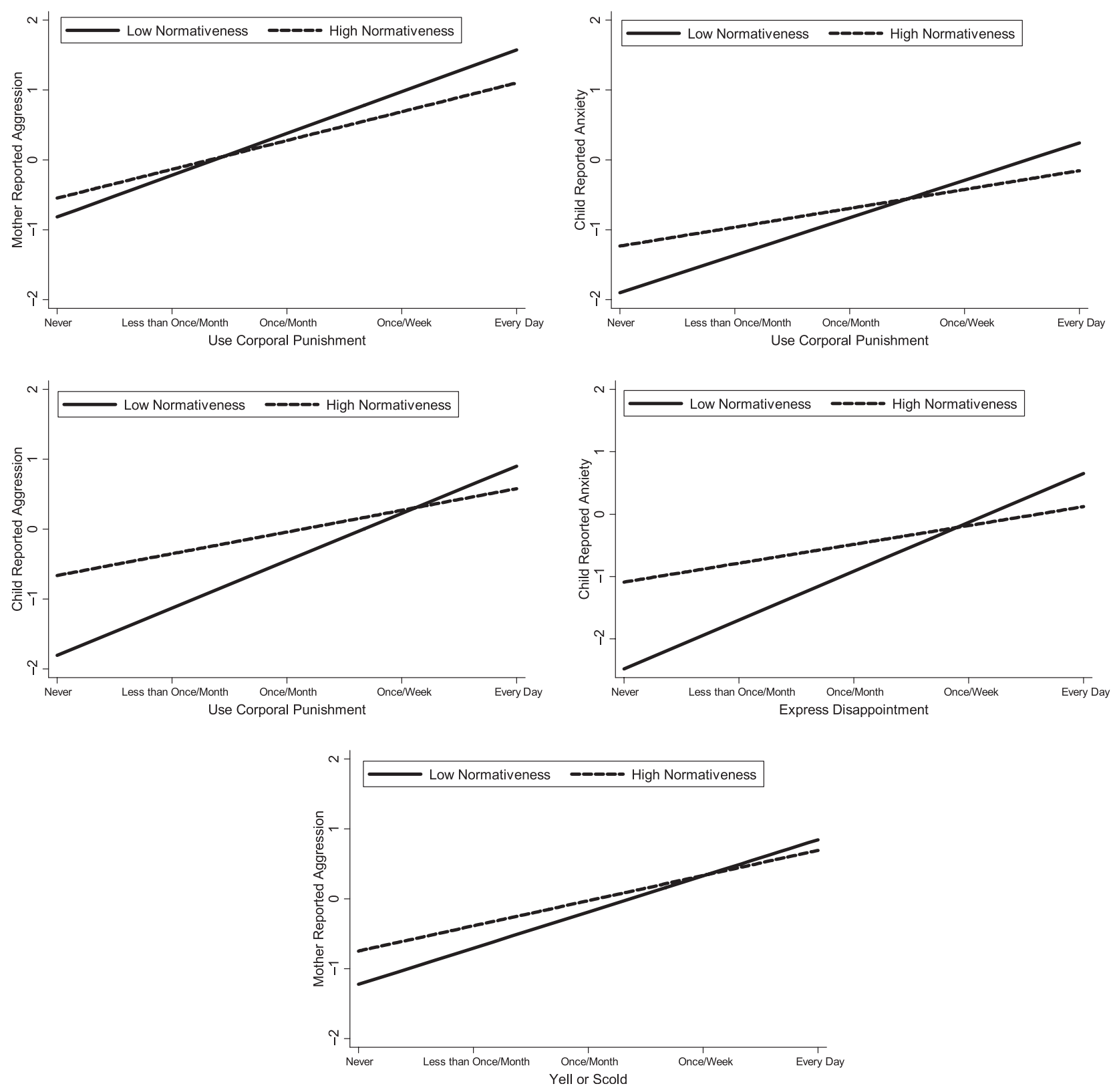

Figure 2. Plots of the links between the frequencies with which mothers use corporal punishment, express disappointment, and yell or scold with children's aggression or anxiety symptoms as moderated by children's perceptions of the normativeness of each discipline technique.

Note. "Low normativeness" and "high normativeness" reflect the frequency with which mothers report using each discipline technique at -1 and $+1 S D$, respectively, from the mean of children's reports of normativeness across the sample.

discipline associated with children's aggressive and anxious behaviors across an international sample made up of families in six countries? The first conclusion to be drawn from our parallel multilevel and fixed effects models that considered all 11 discipline techniques simultaneously is that only three techniques were significantly associated with levels of child aggression and only four techniques were significantly related to levels of child anxiety.
In other words, the frequencies with which mothers in this international sample reported using most of the disciplinary techniques were not associated with their children's aggressive or anxious behaviors. The second conclusion is that none of the discipline techniques was associated with less child aggression or less child anxiety. Using corporal punishment, expressing disappointment, and yelling or scolding were each associated with more 
child aggression, while giving a time-out, using corporal punishment, expressing disappointment, and shaming were associated with more child anxiety.

For the techniques found to be significantly associated with child aggression or anxiety when country was controlled, we added random intercepts to the multilevel models to determine whether there were in fact significant between-country differences in the extent to which that discipline technique was related to child behavior. Of the nine models examined in this way, significant country differences were found only for the association of express disappointment with mother-rated aggression; the association was stronger among families in China, Italy, the Philippines, and Thailand than among families in Kenya. However, normativeness does not explain theses differences; normativeness did not moderate the association of express disappointment with mother-rated aggression in the final set of analyses. Why this particular discipline technique is more strongly associated with mothers' ratings of child aggression in some countries than in others remains a question for future research.

The cross-sectional nature of the data raises the question of direction of effect. Specifically, does parents' use of these discipline techniques predict more aggression in children, or do aggressive children elicit more discipline? The question of whether such associations are evidence of a parent effect or a child effect has been raised most often with regard to parents' use of corporal punishment (Baumrind, Larzelere, \& Cowan, 2002; Larzelere, Kuhn, \& Johnson, 2004). It is undoubtedly true in some cases that aggressive children elicit more parental discipline; difficult children have indeed been found to elicit harsh behavior even from nonfamiliar adults (Anderson, Lytton, \& Romney, 1986). It is a logical extension of this argument that difficult children should elicit more of all forms of discipline from their parents, not just corporal punishment (Larzelere et al., 2004).

Although these data do not permit a rigorous test of this important question (at minimum, longitudinal data would be needed), some patterns of the correlational effects are suggestive of the presence of parent effects on child behavior. First, we did not find that parents use more of all forms of discipline with aggressive children; rather, only 4 of the 11 forms of discipline were significantly associated with child aggression. If aggressive children were eliciting more parent discipline overall, we would have expected them to elicit more of the most frequently reported forms of discipline. However, although mothers reported they teach about good and bad behavior and get child to apologize most often, they were not using these techniques any more frequently for children they rated as high in aggression. These findings are not consistent with a "child effect" explanation.

Second, although it is not hard to imagine an aggressive child eliciting more discipline from a parent, it is less clear whether a child's symptoms of anxiety would elicit discipline, particularly potentially harsh techniques such as corporal punishment and yelling. Rather, longitudinal research has found that parents typically use less, not more, harsh discipline with anxious and fearful children (Kochanska, Aksan, \& Joy, 2007). They do so with good reason: Discipline techniques high in power assertion, including punishment, have been found to substantially undermine moral internalization among children high in fearfulness or anxiety (Kochanska et al., 2007). Children's levels of depression and anxiety have also been found to predict less corporal punishment in particular (Grogan-Kaylor \& Otis, 2007). Clearly these analyses will need to be replicated with quasi-experimental or longitudinal data to definitively identify direction of effect, but our findings for both child aggression and child anxiety are more consistent with a parent effect rather than a child effect explanation.

Our decision to use both multilevel and fixed effects analyses exploited the benefits and reduced the costs of using either method alone. The overwhelming consistency of the results across the two sets of models added to our confidence in the robustness of our findings. We encourage future researchers to similarly employ parallel methods when analyzing complex and nested datasets.

Although the associations of discipline with child behavior were almost entirely consistent across cultures when indexed as countries, we did find some evidence that more proximal measures of culture, namely, children's beliefs about the normativeness of discipline within their local communities, did dampen the associations of three forms of discipline with child behavior. In all cases, however, the slopes were positive, such that more frequent use of a particular discipline was associated with greater child behavior problems; even when moderation was present, the association between a discipline technique and a child outcome never reversed direction. This association is also evident in the higher intercepts for the high normativeness group in all of the graphs of the significant moderations. If children's beliefs about normativeness are largely driven by what they see their own parents doing, then it makes sense that the effects of 
perceived normativeness would be similar in direction and magnitude to the effects of their own parents' use of discipline. It of course may also be that children with higher symptomatology perceive adults in their communities as more punitive. We need to know more about how children form beliefs about normativeness to truly understand these findings.

Mothers' perceptions of normativeness moderated only one of the discipline-child behavior associations. This finding suggests that mothers' perceptions of normativeness and children's perceptions of normativeness may have different functions. Further exploration into how parents develop beliefs about discipline normativeness and into how such beliefs may moderate their own behavior is an exciting avenue for future research.

We had hypothesized that normativeness would moderate the associations of techniques most likely to be perceived as negative events by the child, namely, corporal punishment and yelling, with child behaviors. This was indeed found to be the case. The associations of corporal punishment frequency with child aggression and child anxiety, and of yelling and scolding with child aggression, were less strong when children perceived these techniques to be normative, although again the slope was always positive (more frequent use of the technique associated with a greater number of problem behaviors). We also found the association between expressing disappointment and childreported anxiety to be moderated by both mothers' and children's perceptions of the normativeness of the technique. In our data, normativeness only played a role for the most negative of the discipline techniques, namely corporal punishment and yelling. Given that the findings for express disappointment were similar to these more objectively negative forms of discipline, it appears that when parents express disappointment in their children, children experience that as a distressing event that is linked with more behavior problems the less common it is in the children's community. All other forms of discipline were not affected by normativeness, which suggests to us that the effects of some forms of discipline are robust to community norms. However, given the limited number of significant associations between discipline and child behavior, there is typically no effect of discipline for normativeness to moderate.

Although we worked to ensure the linguistic and cultural equivalence of each discipline technique across the six countries through qualitative interviews and translation and back-translation proce- dures, it is still possible that there remained some cultural differences in the interpretation of the types of discipline techniques or in the extent to which responses are affected by social desirability bias. An important extension of this work would be to determine whether discipline measures created as indigenous to each country would generate other discipline techniques that are used often in some countries while used rarely or not at all in others (i.e., taking a truly "emic" approach; Berry, 1999; Dasen \& Mishra, 2000; Harkness \& Super, 2002). Additionally, the measure with which we asked parents about their disciplinary techniques focused on individual strategies and not on how parents might combine them; more detailed information, such as diary records (e.g., Chapman \& Zahn-Waxler, 1982; Larzelere, Schneider, Larson, \& Pike, 1996), could help identify patterns of disciplinary combinations. We also note that the CBCL and YSR subscales used in this article were only modestly internally consistent for the mothers and children in the Indian sample. This was unexpected given that the CBCL has been used successfully with families from the Indian subcontinent (Shenoy et al., 1998).

This study advances our very limited knowledge about parents' use of a wide range of discipline techniques around the world and about links between use of these techniques and children's aggressive and anxious behaviors. We found little evidence that the associations of these discipline techniques with children's behaviors vary by the country in which families live. However, our findings that children's perceptions of the normativeness of discipline were related directly to their behavior and that they moderated the associations between parent discipline and child behavior confirm a potentially important role for children's perceptions of normativeness in understanding how parent discipline impacts child behavior. We encourage more researchers to consider the role of perceived normativeness in their studies of parental discipline and to assess the opinions of those most affected by discipline, the children themselves.

\section{References}

Achenbach, T. M. (1991a). Manual for the Child Behavior Checklist and 1991 profile. Burlington: University of Vermont, Department of Psychiatry.

Achenbach, T. M. (1991b). Manual for the Youth Self-Report Form and 1991 profile. Burlington: University of Vermont, Department of Psychiatry. 
Achenbach, T. M. (2004). Cross-cultural perspectives on developmental psychopathology. In U. P. Gielen \& J. Roopnarine (Eds.), Childhood and adolescence: Cross-cultural perspectives and applications (pp. 411-429). Westport, CT: Praeger.

Allison, P. (2005). Fixed effects regression methods for longitudinal data using SAS. Cary, NC: SAS Publishing.

Anderson, K. E., Lytton, H., \& Romney, D. M. (1986). Mothers' interactions with normal and conduct-disordered boys: Who affects whom? Developmental Psychology, 22, 604-609.

Artigas, J. (1999). Manifestaciones psicológicas de la epilepsia en la infancia. Revista de Neurologia, 28, S135-S141.

Baumrind, D., Larzelere, R. E., \& Cowan, P. A. (2002). Ordinary physical punishment: Is it harmful? Comment on Gershoff (2002). Psychological Bulletin, 128, 580-589.

Berry, J. W. (1999). Emic and etics: A symbiotic conception. Culture and Psychology, 5, 165-171.

Bornstein, M. H. (1995). Form and function: Implications for studies of culture and human development. Culture and Psychology, 1, 123-137.

Chapman, M., \& Zahn-Waxler, C. (1982). Young children's compliance and noncompliance to parental discipline in a natural setting. International Journal of Behavioral Development, 5, 81-94.

Collins, W. A., Madsen, S. D., \& Susman-Stillman, A. (2002). Parenting during middle childhood. In M. H. Bornstein (Ed.), Handbook of parenting: Vol. 3. Being and becoming a parent (2nd ed., pp. 73-101). Mahwah, NJ: Erlbaum.

Crijnen, A. A. M., Achenbach, T. M., \& Verhulst, F. C. (1997). Comparisons of problems reported by parents of children in 12 cultures: Total problems, externalizing, and internalizing. Journal of the American Academy of Child and Adolescent Psychiatry, 36, 1269-1277.

Dasen, P. R., \& Mishra, R. C. (2000). Cross-cultural views on human development in the third millennium. International Journal of Behavioral Development, 24, 428-434.

Deater-Deckard, K., \& Dodge, K. A. (1997). Externalizing behavior problems and discipline revisited: Nonlinear effects and variation by culture, context, and gender. Psychological Inquiry, 8, 161-175.

Deater-Deckard, K., Dodge, K. A., \& Sorbring, E. (2005). Cultural differences in the effects of physical punishment. In M. Rutter \& M. Tienda (Eds.), Ethnicity and causal mechanisms (pp. 204-226). Cambridge, UK: Cambridge University Press.

Dodge, K. A., \& Pettit, G. S. (2003). A biopsychosocial model of the development of chronic conduct problems in adolescence. Developmental Psychology, 39, 349-371.

Dong, Q., Wang, Y., \& Ollendick, T. H. (2002). Consequences of divorce on the adjustment of children in China. Journal of Clinical Child and Adolescent Psychology, 31, 101-110.

Ember, C. R., \& Ember, M. (2005). Explaining corporal punishment of children: A cross-cultural study. American Anthropologist, 107, 609-619.
Florencio, C. (1988). Nutrition, health and other determinants of academic achievement and school-related behavior of Grades one to six pupils. Quezon City, Philippines: University of the Philippines.

Gershoff, E. T. (2002). Corporal punishment by parents and associated child behaviors and experiences: A meta-analytic and theoretical review. Psychological Bulletin, 128, 539-579.

Giles-Sims, J., Straus, M. A., \& Sugarman, D. B. (1995). Child, maternal, and family characteristics associated with spanking. Family Relations, 44, 170-176.

Gill, R., \& Kang, T. (1995). Relationship of home environment with behavioural problems of pre-school children. Indian Journal of Psychometry and Education, 26, 77-82.

Grogan-Kaylor, A., \& Otis, M. D. (2007). The predictors of parental use of corporal punishment. Family Relations, 56, 80-91.

Grusec, J. E., \& Goodnow, J. J. (1994). Impact of parental discipline methods on the child's internalization of values: A reconceptualization of current points of view. Developmental Psychology, 30, 4-19.

Guo, L., Leung, P. W. L., Ho, T., Xiong, S., Li, Z., Deng, Z., et al. (2000). A cross-site comparing study on child behavior and emotional problems in Hong Kong and Chengdu. Chinese Mental Health Journal, 14, 145-148.

Harkness, S., \& Super, C. M. (2002). Culture and parenting. In M. H. Bornstein (Ed.), Handbook of parenting: Vol. 2. Biology and ecology of parenting (2nd ed., pp. 253-280). Mahwah, NJ: Erlbaum.

Hoffman, M. L. (1983). Affective and cognitive processes in moral internalization. In E. T. Higgins, D. N. Ruble, \& W. W. Hartup (Eds.), Social cognition and social development (pp. 236-274). New York: Cambridge University Press.

Hofstede, G. (2001). Culture's consequences: Comparing values, behaviors, institutions, and organizations across nations (2nd ed.). Newbury Park, CA: Sage.

Holden, G. W., Miller, P. C., \& Harris, S. D. (1999). The instrumental side of corporal punishment: Parents' reported practices and outcome expectancies. Journal of Marriage and the Family, 61, 908-919.

Hox, J. (2002). Multilevel analysis: Techniques and applications. Mahwah, NJ: Erlbaum.

Kochanska, G., Aksan, N., \& Joy, M. E. (2007). Children's fearfulness as a moderator of parenting in early socialization: Two longitudinal studies. Developmental Psychology, 43, 222-237.

Korbin, J. E. (2003). Children, childhoods, and violence. Annual Review of Anthropology, 32, 431-446.

Lansford, J. E., Chang, L., Dodge, K. A., Malone, P. S., Oburu, P., Palmérus, K., et al. (2005). Physical discipline and children's adjustment: Cultural normativeness as a moderator. Child Development, 76, 12341246.

Larzelere, R. E., Kuhn, B. R., \& Johnson, B. (2004). The intervention selection bias: An unrecognized confound in intervention research. Psychological Bulletin, 130, 289-303. 
Larzelere, R. E., Schneider, W. N., Larson, D. B., \& Pike, P. L. (1996). The effects of discipline responses in delaying toddler misbehavior recurrences. Child and Family Behavior Therapy, 18, 35-57.

Lepper, M. R. (1983). Social control processes and the internalization of social values: An attributional perspective. In E. T. Higgins, D. N. Ruble, \& W. W. Hartup (Eds.), Social cognition and social development (pp. 294-330). New York: Cambridge University Press.

Maas, C. J. M., \& Hox, J. J. (2004). Robustness issues in multilevel regression analysis. Statistica Neerlandica, 58(2), 127-137.

Mistry, J., Chaudhuri, J. H., \& Diez, V. (2003). Ethnotheories of parenting: At the interface between culture and child development. In R. M. Lerner, D. Wertlieb, \& F. Jacobs (Eds.), Handbook of applied developmental science: Vol. 1. Applying developmental science for youth and families: Historical and theoretical foundations (pp. 233-257). Thousand Oaks, CA: Sage.

Rao, N., McHale, J. P., \& Pearson, E. (2003). Links between socialization goals and child-rearing practices in Chinese and Indian mothers. Infant and Child Development, 12, 475-492.

Raudenbush, S. W., \& Bryk, A. S. (2002). Hierarchical linear models: Applications and data analysis methods. Thousand Oaks, CA: Sage.

Ripoll-Nuñez, K. J., \& Rohner, R. P. (2006). Corporal punishment in cross-cultural perspective: Directions for a research agenda. Cross-Cultural Research, 40, 220-249.

Rogoff, B. (2003). The cultural nature of human development. New York: Oxford University Press.

Rothbaum, F., Morelli, G., Pott, M., \& Liu-Constant, Y. (2000). Immigrant-Chinese and Euro-American parents' physical closeness with young children: Themes of family relatedness. Journal of Family Psychology, 14, 34348.

Save the Children. (2008). The Child Development Index: Holding governments to account for children's well-being. Retrieved December 11, 2008, from http://www. savethechildren.org.uk/en/docs/child-developmentindex.pd

Sears, R. R., Maccoby, E. E., \& Levin, H. (1957). Patterns of child rearing. New York: Harper \& Row.

Shenoy, J., Kapur, M., \& Kaliaperumal, V. G. (1998). Psychological disturbance among 5- to 8-year-old school children: A study from India. Social Psychiatry and Psychiatric Epidemiology, 33, 66-73.

Socolar, R. R. S., Savage, E., \& Evans, H. (2007). A longitudinal study of parental discipline of young children. Southern Medical Journal, 100, 472-477.

Stata Corporation. (2005). Longitudinal/panel data reference manual. College Station, TX: Stata Press.

Straus, M. A. (1979). Measuring intrafamily conflict and violence: The Conflict Tactics Scale. Journal of Marriage and the Family, 41, 75-88.

Straus, M. A., \& Mouradian, V. E. (1998). Impulsive corporal punishment by mothers and antisocial behavior and impulsiveness of children. Behavioral Sciences and the Law, 16, 353-374.

Straus, M. A., \& Stewart, J. H. (1999). Corporal punishment by American parents: National data on prevalence, chronicity, severity, and duration, in relation to child and family characteristics. Clinical Child and Family Psychology Review, 2, 55-70.

Super, C. M., \& Harkness, S. (1986). The developmental niche: A conceptualization at the interface of child and culture. International Journal of Behavioural Development, 9, 545-569.

Weisz, J. R., Sigman, M., Weiss, B., \& Mosk, J. (1993). Parent reports of behavioral and emotional problems among children in Kenya, Thailand, and the United States. Child Development, 64, 98-109.

Weisz, J. R., Suwanlert, S., Chaiyasit, W., Weiss, B., Achenbach, T. M., \& Eastman, K. L. (1993). Behavioral and emotional problems among Thai and American adolescents: Parent reports for ages 12-16. Journal of Abnormal Psychology, 102, 395-403.

World Bank. (2008, October). Revised estimates for PPP GNI per capita income and PPP GDP. Retrieved December 11, 2008, from http://go.worldbank.org/B5PYF93QF0 